\title{
O Serviço de Telemedicina de Coimbra Melhora o Acesso à Especialidade de Cardiologia Pediátrica em Cabo Verde
}

\author{
Coimbra Telemedicine Service Improves Access to \\ Pediatric Cardiology in Cape Verde
}

\author{
Eduardo CASTELA $\square^{1,2,3}$ \\ Acta Med Port 2017 Apr;30(4):253-254 - https://doi.org/10.20344/amp.9034
}

Palavras-chave: Cabo Verde; Cardiologia; Criança; Doenças do Coração; Pediatria; Portugal; Telemedicina

Keywords: Cape Verde; Cardiology; Child; Heart Diseases; Pediatrics; Portugal; Telemedicine

A telemedicina, na área da Cardiologia Pediátrica, tem mostrado ser um meio complementar de diagnóstico com comprovada eficácia. O dinamismo subjacente a esta técnica, permite em tempo real, quer em casos eletivos quer em situações de urgência, a realização de teleconsultas à distância. $\mathrm{O}$ acesso rápido e direto a uma consulta de especialidade, aspetos economicistas e pedagógicos representam algumas das vantagens que definem e a tornam aliciante.

No Serviço de Cardiologia Pediátrica (SCP) do Centro Hospitalar e Universitário de Coimbra (CHUC), esta atividade iniciou-se em 1998 evidenciando-se, desde essa altura, um manifesto interesse no seu desenvolvimento, comprovado pelo número crescente de teleconsultas e pelas parcerias que atualmente existem, tanto a nível nacional como também com os PALOP. ${ }^{1}$ Tendo como base o Hospital Pediátrico-CHUC em Coimbra, praticamente todos os hospitais com serviços de Pediatria da região Centro do País estão abrangidos pela rede da telemedicina. Fora da região Centro salienta-se o Hospital de Vila Real. Relativamente aos PALOP, destacam-se Angola e Cabo Verde, São Tomé e Príncipe e, muito proximamente, Guiné. O intercâmbio com estes polos reveste-se de particular importância pelo que possibilita o acesso a tratamentos mais diferenciados, consoante o quadro clínico. Permite também o contato com doenças de menor prevalência no nosso âmbito, estabelecendo um processo de aprendizagem recíproca e saudável.

Como com qualquer empreendimento, o ponto de partida para o sucesso baseia-se, logo à partida, no interesse despontado pelo produto, neste caso a telemedicina, amplamente comprovado desde a sua criação quer em termos quantitativos quer qualitativos. De seguida, e revestido da maior importância e pela responsabilidade exigida, existe a necessidade de uma formação rigorosa de profissionais de saúde na área da cardiologia pediátrica e ecocardiografia. Face à inexistência de cardiologistas pediátricos em hospitais dos PALOP, os médicos desses países manifestaram interesse pela especialidade e com aptidão para técnicas ecocardiográficas e realizam um período de formação no nosso serviço, iniciando posteriormente esta atividade no seu local de trabalho habitual. Face à essência da telemedicina, o aspeto formativo é naturalmente mantido, outra das vantagens já referidas desta prática.

Um programa de telemedicina exige, para além da formação de profissionais nas respetivas áreas, o equipamento necessária para a realização da teleconsulta. Salientam-se três aspetos importantes: a plataforma, o ecógrafo e, para a transmissão adequada de dados, a largura da banda nos respetivos hospitais. ${ }^{1}$ A plataforma utilizada tem o nome de Medigraf - sistema de telemedicina desenvolvido pela PT-Inovação. Relativamente ao tipo de ecógrafo, a aquisição destes está dependente das respetivas administrações hospitalares. Estes, no entanto, devem ter o software indispensável à realização de ecocardiografia bidimensional, modo $\mathrm{M}$ e doppler a cores. A largura da banda hospitalar deve respeitar os requisitos mínimos para uma transmissão que se quer em tempo real, ou seja rápida e nítida

Uma análise entre os ganhos para a saúde, por todos nós conhecidos e sobretudo com a utilização desta ferramenta com os PALOP.

Um dos melhores exemplos de sucesso em telemedicina é a parceria com Cabo Verde que tem demonstrado quanto tem sido útil para todos os intervenientes. ${ }^{2}$ Iniciámos as diligências para implementação da telemedicina com este país em 2006, com reuniões para discutir a sua implementação e com estágios de colegas de Cabo Verde no nosso Serviço de Cardiologia Pediátrica - CHUC. Assim, estiveram neste serviço nove médicos, tanto da Praia como do Mindelo, colaboraram com todas as actividades do dia-a-dia do SCP e praticaram ecocardiografia pediátrica e cardiologia fetal.

Iniciamos a telemedicina semanalmente em Maio de 2009, e de então para cá efectuámos com este país 477 teleconsultas. Destes foram evacuados para tratamento no

1. Serviço de Cardiologia Pediátrica. Centro Hospitalar e Universitário de Coimbra. Coimbra. Portugal.

2. Presidente. Associação Portuguesa de Telemedicina. Ordem dos Médicos. Coimbra. Portugal.

3. Promotor Interno de Telesaúde. Centro Hospitalar e Universitário de Coimbra. Coimbra. Portugal.

$\square$ Autor correspondente: Eduardo Castela. ecastela@hotmail.com

Recebido: 22 de março de 2017 - Aceite: 03 de abril de 2017 | Copyright @ Ordem dos Médicos 2016 
nosso serviço cerca de 90 crianças com patologia cardíaca para tratamento.

Na nossa experiência, a telemedicina não só tem demonstrado ser uma prática segura e eficaz no diagnóstico e

\section{REFERENNCIAS}

1. Castela E, Ramalheiro G, Pires A, Carreia LM, Santos I, Costa H, et al. Five years of teleconsultation: experience of the cardiology department of Coimbra Pediatric Hospital. Rev Port Cardiol. 2005;24:835-40. seguimento de crianças com suspeita de cardiopatia, mas igualmente um instrumento de complementaridade entre um centro de referência e os respetivos colaboradores.

2. Lapão LV, Correia A. Improving access to pediatric cardiology in Cape Verde via a collaborative international telemedicine service. Stud Heath Technol Inform. 2015:51-7. 